Acta Theriologica 44 (4): 337-343, 1999.

PL ISSN 0001-7051

\title{
Behavioural variation in two populations of root voles
}

\author{
Joanna KAPUSTA, Karol PACHINGER and Anna MARCHLEWSKA-KOJ*
}

Kapusta J., Pachinger K. and Marchlewska-Koj A. 1999. Behavioural variation in two populations of root voles. Acta Theriologica 44: 337-343.

Significant morphological and physiological variations between root vole Microtus oeconomus (Pallas, 1776) populations have been found. Behavioural differences between two geographically separated populations were found in this study. Ultrasonic vocalization and behavioural interaction (non-aggressive and aggressive approaches) were monitored during 10-min encounters. Ultrasounds were monitored during encounters involving all possible combinations of males and females of two populations, called here southern (Prague, Czech Republic) and northern (Białowieża, Poland). The northern male-male combination did not produce ultrasounds. In both populations, males exhibited more aggressive behaviour than females did. Since $M$. oeconomus females are highly territorial and the home ranges of males overlap, the agonistic behaviour of males may enable them to control a larger area with greater numbers of receptive females. We also found significant differences in behavioural activity between the two investigated populations: southern $M$. oeconomus showed higher activity than northern root voles did. Separate populations which differ morphologically and behaviourally have much to tell us about speciation processes. Behavioural divergence can lead to reproductive isolation and thus create separate gene pools.

Department of Mammalian Reproduction, Institute of Environmental Sciences, Jagiellonian University, Ingardena 6,30-060 Kraków, Poland, e-mail: amkoj@eko.uj.edu.pl (JK, AM-K); Department of Zoology, Comenius University, 84215 Bratislava, Slovak Republic (KP)

Key words: Microtus oeconomus, root voles, behaviour, ultrasounds, aggression

\section{Introduction}

Root voles Microtus oeconomus (Pallas, 1776) have a wide geographic range in Europe: they are present in Scandinavia, the Netherlands, Germany and Poland. Isolated populations have been also found in the Czech Republic, Hungary and Slovakia. Significant morphological and physiological variations have been described between individuals from the same population (Markowski 1980). Two geographically separated populations from southern and northern Norway show differences in reproductive activity (Ims 1994, 1997). Based on morphological differences, root voles from Southern Europe have been described as the subspecies Microtus oeconomus mehelyi (Bauer 1953).

*To whom correspondence should be addressed 
Root voles are relatively easy to breed in the laboratory and thus have become the object of experiments on several aspects of population dynamics (Johannesen and Ims 1996). For example, significant differences in litter size and offspring survival have been found in two investigated populations showing similar paternal behaviour (dos Santos et al. 1995).

We studied adult Microtus oeconomus from two populations, called here northern (Białowieża, Poland) and southern (trapped near Prague, Czech Republic). There is a considerable body of information about the natural habitats (Buchalczyk and Pucek 1968), biology (Gębczyńska 1970, Gębczyńska and Gębczyński 1971), growth and reproduction (Gliwicz 1996) of root voles from Northern Poland. The natural habitat of $M$. oeconomus mehelyi is wet meadow partly overgrown by shrubs and bushes near Prague (K. Pachinger, unpub. obs.) but the biology of this population has not been investigated. Since the distance between Białowieża and Prague is over $1000 \mathrm{~km}$, root voles from these two areas are a good model for comparing the behaviours of populations of the same species which might differ genetically.

This study compared the behaviours of female and male root voles from these two geographically separated populations. Attacks and non-aggressive approaches during intermale, interfemale or male-female encounters were recorded during test sessions. Ultrasonic calls, which are regarded as a part of social interaction in many species of rodents, were monitored, recorded and analyzed.

\title{
Material and methods
}

\begin{abstract}
Animals
Microtus oeconomus mehelyi from the southern population were trapped near Prague in 1994 and bred in the laboratory of the Department of Zoology, Comenius University, Bratislava, Slovakia. M. oeconomus, northern population, came from Białowieża, Poland. They were trapped in an experimental area of the Mammal Research Institute of the Polish Academy of Sciences in Białowieża between April and June 1997 and transferred to Kraków. These root voles were kept in controlled laboratory conditions in Kraków for two months before testing.

All tested animals were maintained in similar laboratory conditions in Bratislava and in Kraków. They were housed singly at $18-20^{\circ} \mathrm{C}$ with a $14 \mathrm{~h}$ photoperiod (lights on at 7:00 a.m.). Hay, apples and grain (wheat and oats) were provided every day.

Behaviour and ultrasonic vocalizations of $M$. oeconomus mehelyi were recorded in Bratislava. $M$. oeconomus from the Białowieża population were studied in the Department of Mammalian Reproduction, Institute of Environmental Sciences, Jagiellonian University, Kraków, Poland. The experimental conditions in the two laboratories were identical. All the tested animals were at least one year old. Eight females and 8 males of $M$. oeconomus mehelyi (southern population) and 5 females and 5 males root voles from Białowieża (northern population) were studied. Each animal was tested twice. They were always matched with a partner of similar body size, and the second test always involved different partners. Intervals between behavioural tests of the same animal were at least one week.
\end{abstract}

\section{Behavioural test}

A singly maintained female or male was transferred from the home cage to a glass vivarium (40 $\times$ $20 \times 25 \mathrm{~cm}$ ) with the floor covered by clean wood shavings. The vivarium was divided by a wooden 
partiton into halves, each occupied by one animal, and left undisturbed for 3-4 h. After this period the partiton was removed and behaviour recorded in a 10-min session. Observations were made between 11:00 a.m. and 1:00 p.m.

For each test session, total activity was assessed as the total number of non-aggressive and aggresive acts. Non-aggressive behaviour was estimated by the latency (in sec.) to first approach and the nimber of approaches. The latency to first attack and the number of attacks (boxing and wresting) were used as indicators of aggressive behaviour.

The animals' ultrasonic vocalizations were recorded during each session. Calls were monitored with a ultrasound receiver suspended $5 \mathrm{~cm}$ above the tested animals. The microphone was connected to a QMC S25 ultrasound detector coupled to a Sony HX PRO cassette recorder. Samples of recorded ultrasinic calls were analyzed using the Canary program (Cornell Bioacoustics Workstation, Version 1.2). The number of calls, frequencies and duration of the fundamental frequency were estimated.

\section{Statistical analysis}

The experimental groups were compared using one-way analysis of variance (ANOVA) and the MannWhitney $U$-test (Sokal and Rohlf 1981).

\section{Results}

The behaviour of root voles from two populations during 10-min encounters was analyzed. In each experimental group 8 pairs of voles from the southern population and 5 pairs of northern animals were tested. The results of observations of the tested same-sex or different-sex pairs are summarized in Fig. 1. Behavioural differences between the animals from the northern and southern populations were
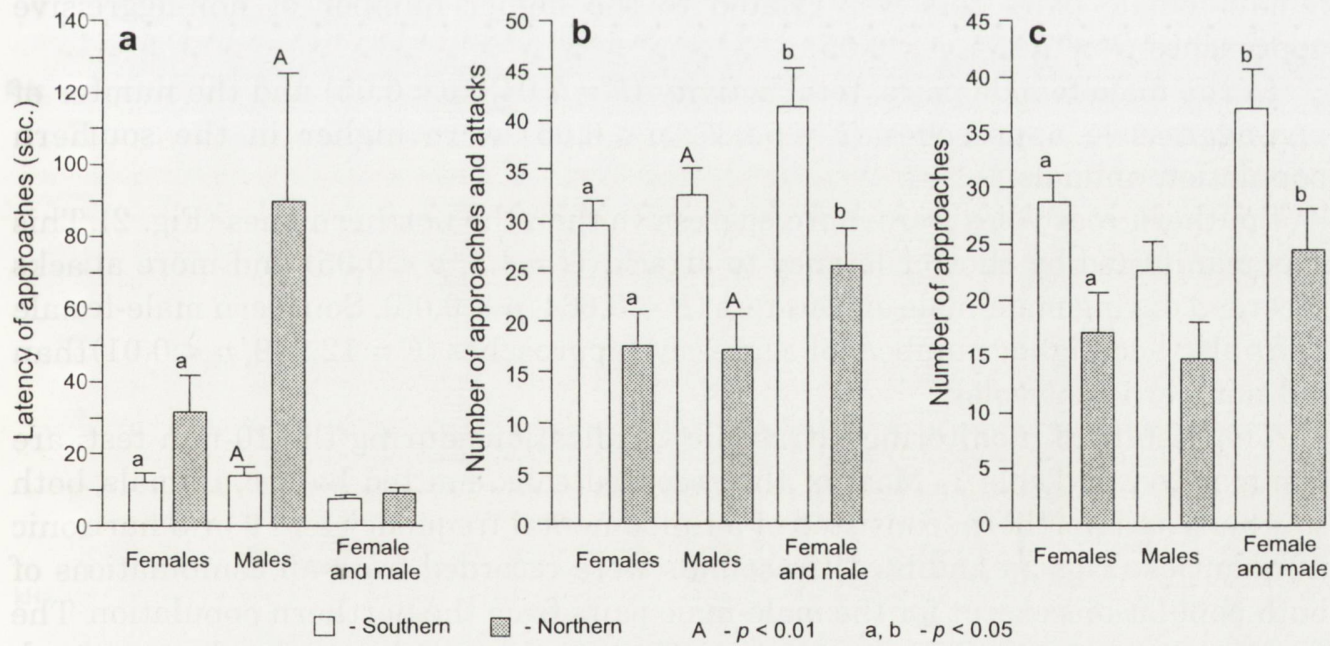

Fig. 1. Behaviour of female and male root voles from southern and northern populations tested in pairs durin 10 -min encounters. Means ( \pm SEM). (a) Latency to first approach. (b) Total activity (approaches and aitacks) of pairs. (c) Number of approaches within pairs. 

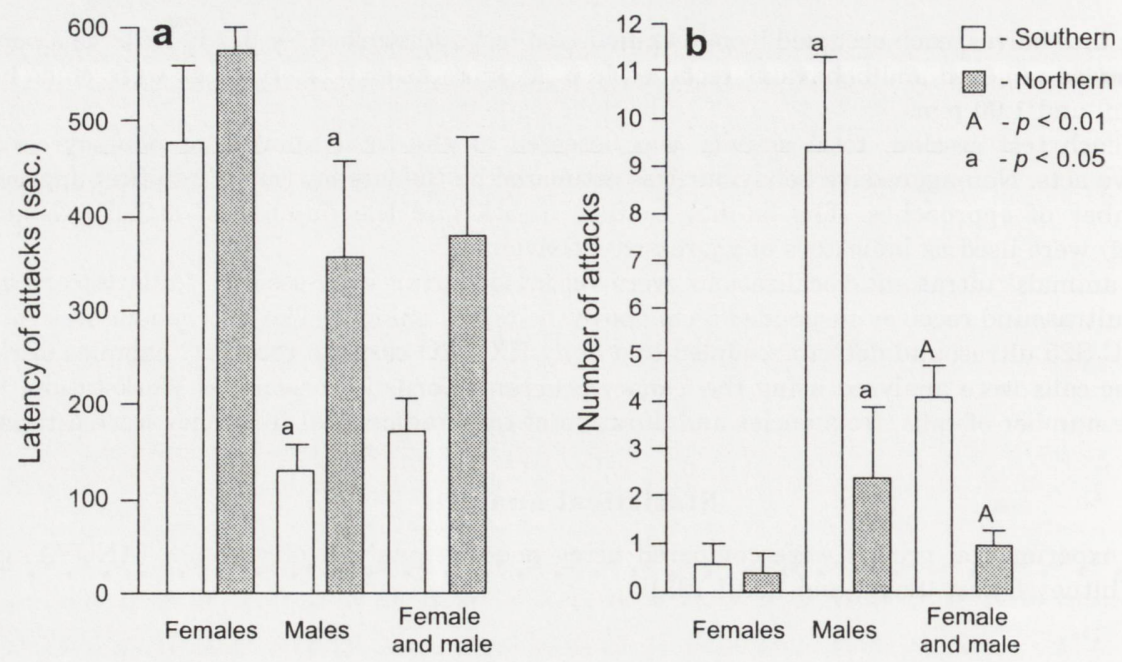

Fig. 2. Aggressive behaviour of female and male root voles from southern and northern populations tested in pairs during 10-min encounters. Means ( \pm SEM). (a) Latency to first attack. (b) Number of attacks within pairs.

found. Latency to first approach by females $(U=3.5, p<0.05)$ and males $(U=2.0$, $p<0.01$ ) was shorter in the southern population representatives. Interfemale and intermale total activity was significantly higher in southern root voles than in northern ones $(F=8.076, p<0.05$ and $F=12.338, p<0.01$, respectively). In female-female pairs this was related to the higher number of non-aggressive approaches $(F=7.754, p<0.05)$.

In the male-female pairs, total activity $(F=7.048, p<0.05)$ and the number of non-aggressive approaches $(F=5.637, p<0.05)$ were higher in the southern population animals.

Southern root voles were more aggressive than the northern ones (Fig. 2). This was manifested by shorter latency to attack $(U=4.5, p<0.05)$ and more attacks recorded during male-male encounters $(F=6.664, p<0.05)$. Southern male-female pairs also had higher numbers of aggressive approaches $(F=12.249, p<0.01)$ than did northern root voles.

The results of monitoring ultrasonic vocalizations during the 10-min tests are summarized in Table 1. Most of the recorded calls emitted by the animals, both southern and northern, consisted of a fundamental frequency and 2 or 3 harmonic frequencies (Figs 3a and b). Ultrasounds were recorded from all combinations of both populations except for the male-male pairs from the northern population. The results show great within-group variation in the numbers of pulses emitted. Analysis of fundamental frequencies did not indicate differences in the frequency or duration of vocalized sounds. The small number of recorded pulses did not permit statistical comparison. 
Table 1. Ultrasonic vocalization of root voles from southern and northern populations tested in pairs during 10 -min encounters $(\mathrm{Mean} \pm \mathrm{SEM}) .{ }^{*}$ - range in parentheses.

\begin{tabular}{|c|c|c|c|c|c|}
\hline \multirow{2}{*}{ Tested pairs } & \multicolumn{2}{|c|}{ No. pairs } & \multirow{2}{*}{ No. calls } & \multirow{2}{*}{ Frequency $\mathrm{kHz}$} & \multirow{2}{*}{ Duration msec. } \\
\hline & tested & vocalized & & & \\
\hline \multicolumn{6}{|c|}{ Female-female } \\
\hline Southern & 8 & 8 & $40.63(15-100)^{*}$ & $35.16 \pm 1.48$ & $19.55 \pm 1.79$ \\
\hline Northern & 5 & 4 & $2(1-3)$ & $34.55 \pm 1.26$ & $17.32 \pm 2.72$ \\
\hline \multicolumn{6}{|c|}{ Male-male } \\
\hline Southern & 8 & 6 & $18.33(5-50)$ & $31.66 \pm 1.07$ & $14.92 \pm 1.40$ \\
\hline Northern & 5 & 0 & - & - & - \\
\hline \multicolumn{6}{|c|}{ Female-male } \\
\hline Southern & 8 & 8 & $49.38(20-140)$ & $31.98 \pm 1.16$ & $21.20 \pm 1.80$ \\
\hline Northern & 5 & 3 & $6.3(3-13)$ & $30.58 \pm 1.76$ & $16.66 \pm 2.27$ \\
\hline
\end{tabular}
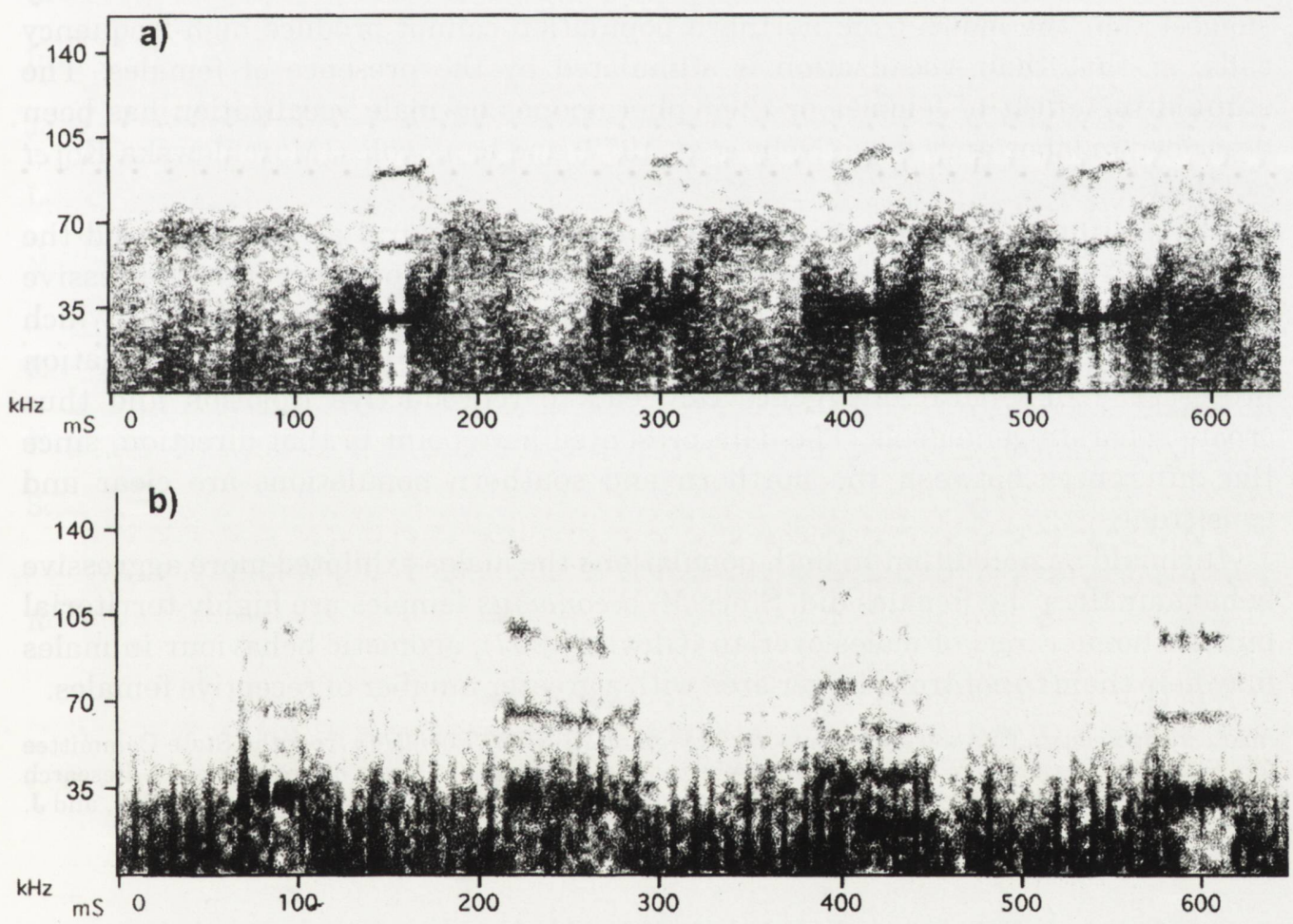

Fig. 3. Sonograms of ultrasonic vocalizations of root voles recorded during tests of male-female pairs. (a) Southern population. (b) Northern population. 


\section{Discussion}

Ultrasonic vocalization in rodents can be part of courtship or aggressive behaviour in unisexual groups. Rodent species differ in their ability to vocalize. In laboratory mice (Nyby et al. 1977) and bank voles (Marchlewska-Koj et al. 1994) only males produced high-frequency calls, whereas in pine voles (Cherry and Lepri 1986), prairie voles (Lepri et al. 1988) and collared lemmings (Brook and Banks 1973) both sexes emit ultrasounds. Gerbillus species also emit ultrasounds during male-female encounters (Dempster and Perrin 1991) but they differ in acoustic signals. The differences are more pronounced between the sympatric species Desmodillus auricularis, Tatera leucogaster and T. brantsii than between the closely related allopatric T. brantsii and T. afra (Dempster and Perrin 1994). Our results provide evidence that different populations of a species may differ in their vocalization ability. Female and male root voles from the southern population produced high-frequency calls in the presence of the same or different sex. In northern voles, vocalization was recorded during behavioural tests of female-female or female-male pairs. The lack of ultrasounds during male-male encounters may suggest that the males from northern population cannot produce high-frequency calls, or that their vocalization is stimulated by the presence of females. The stimulating effect of females or their pheromones on male vocalization has been described in laboratory mice (Nyby et al. 1977) and bank voles (Marchlewska-Koj et al. 1994).

The southern $M$. oeconomus showed higher behavioural activity than did the northern root voles. In females this was the result of more non-aggressive approaches, and in males the result of more attacks. Separated populations which differ morphologically and behaviourally have much to tell us about speciation processes. Behavioural divergence can lead to reproductive isolation and thus create separate gene pools. The data presented here point in that direction, since the differences between the northern and southern populations are clear and consistent.

It should be noted that in both populations the males exhibited more aggressive behaviour then the females did. Since M. oeconomus females are highly territorial but the home range of males overlap (Gliwicz 1997), agonistic behaviour in males may help them to control a larger area with a greater number of receptive females.

Acknowledgements: This work was supported by grant KBN 387/P04/95/08 from the State Committee for Scientific Research, Warsaw, Poland. We thank Professor Z. Pucek of the Mammal Research Institute of Polish Academy of Sciences in Białowieża for providing us with Microtus oeconomus, and J. Gliwicz and an anonymous reviewers for valuable comments.

\section{References}

Bauer K. 1953. Zur Kenntnis von Microtus oeconomus mehelyi Ehik. Zoologische Jahrbücher (Jena) 82: $70-94$. 
Brooks R. J. and Banks E. M. 1973. Behavioural biology of the collared lemming [Dicrostonyx groenlandicus (Traill)]: An analysis of acoustic communication. Animal Behavioural Monography 6: 2-3 (Pont 1).

Buchalczyk T. and Pucek Z. 1968. Estimation of the numbers of Microtus oeconomus using the Standard Minimum method. Acta Theriologica 13: 461-482.

Cherry J. A. and Lepri J. J. 1986. Sexual dimorphism and gonadal control of ultrasonic vocalizations in adult pine voles, Microtus pinetorum. Hormones and Behavior 20: 34-48.

Dempster E. R. and Perrin M. R. 1991. Ultrasonic vocalization od six taxa African gerbils (Rodentia: Gerbillinae). Ethology 88: 1-10.

Dempster E. R. and Perrin M. R. 1994. Divergence in acoustic repertoire of sympatric and allopatric gerbil species (Rodentia: Gerbillinae) Mammalia 58: 93-104

dos Santos E. M., Andreassen H. P. and Ims R. A. 1995. Differential inbreeding tolerance in two geographically distinct strains of root voles Microtus oeconomus. Ecography 18: 238-247.

Gębczyńska Z. 1970. Bioenergics of a root vole population. Acta Theriologica 15: 33-60.

Gębczyńska Z. and Gębczyński M. 1971. Length and weight of the alimentary tract of the root vole. Acta Theriologica 16: 359-369.

Gliwicz J. 1996. Life history of voles: growth and maturation in seasonal cohorts of the root vole. Miscel.lània Zoològica 19(1): 1-12.

Gliwicz J. 1997. Space use in the root vole: basic patterns and variability. Ecography 20: 383-389.

Ims R. A. 1994. Litter sex ratio variation in laboratory colonies of two geographically distinct strains of the root vole Microtus oeconomus. Ecography 17: 141-146.

Ims R. A. 1997. Determinants of geographic variation in growth and reproductive traits in the root vole. Ecology 78: 461-470.

Johannesen E. and Ims R. A. 1996. Modelling survival rates: habitat fragmentation and destruction in root vole experimental populations. Ecology 77: 1196-1209.

Lepri J. J., Theodorides M. and Wysocki C. J. 1988. Ultrasonic vocalization by adult prairie voles, Microtus ochrogaster. Experientia 44: 271-273

Marchlewska-Koj A., Kapusta J., Sales D. G. and Kruczek M. 1994. Ultrasonic calls of bank voles in response to conspecific chemosignals. [In: Advances in the Biosciences, vol. 93. R. Apfebach, D. Müller-Schwarze, K. Reutter and E. Weiler, eds]. Pergamon Press, Oxford: 371-376.

Markowski J. 1980. Morphometric variability in a population of the root vole. Acta Theriologica 25: $155-200$.

Nyby J., Wysocki Ch. J., Whitney G. and Dizinno G. 1977. Pheromonal regulation of male mouse ultrasonic courtship (Mus musculus). Animal Behaviour 25: 333-341.

Sokal R. R. and Rohlf F. J. 1981. Biometry, 2nd edition. W. H. Freeman and Company, New York: 321-344.

Received 9 June 1998, accepted 10 March 1999. 